\title{
Design, Assessment and Choice of Personal Account Incentives
}

\author{
Xiaoying Dong ${ }^{1}$ \\ ${ }^{1}$ Harbin Commercial University, Harbin, China \\ *Corresponding author. Email: 1353203232@qq.com
}

\begin{abstract}
It is well known that the urban employees' pension is consist of the basic pension, transitional pension and personal account pension. How to inspire the insured to renew and improve the driving force of the employee, is also an urgent problem to be solved. This paper designs four urban workers 'pension incentive programs, by comparing the regular deposit interest rates, social average salary growth rates, and the national social security fund investment yield, and taking the program Invitation and steady and long-term development into consideration, and then select the best one.
\end{abstract}

Keywords: Urban workers basic pension insurance, Personal account, Personal account incentive program.

\section{INTRODUCTION}

The most important endowment insurance in my country's social insurance is the basic endowment insurance of urban employees. In 1995 and 1997, the relevant documents clearly established the "Accounts Combination", and the pension insurance of urban employee was established and implemented in my country. In 2005, the State Council issued the "Decision on Perfecting the Basic Endowment Insurance System of Enterprise Workers" (Guofa [2005] No. 38), and the measures of the pension of urban enterprises in the text have made major adjustments, and the urban workers are stated. The only source of personal account funds is personal payment. This policy is to expand the coverage of the basic endowment insurance system of urban employees, but also to solve a series of issues caused by "Accounting Combination".

According to Sun Yat-sen University, "my country's Labor Dynamic Survey (CLDS)" shows that the capital of urban employees of urban employees is $13.28 \%$, and we can see that the number of new income groups is too low, and due to Restricted to the level of self-education, the reduction of the low-income groups in the urban low-income groups is much more. According to statistics from my country's human resources and social security bureaus, 278.26 million employees at the end of 2016, an increase of 16.07 million in the last year. At the end of 2017, the national insured employees were 292.68 million, an increase of 14.41 million in the end of 2016. In 2018, 3010,400 people in the country, increased by 8.36 million in 2017. In 2019, the participation of 311.77 million employees, add 1074 Ten thousand people. my country's participation in urban employee's basic pension insurance has gradually decreased, and we should take measures to in time to carry out the reform of urban workers' pension insurance system, incentive more people participate in basic endowment insurance for urban workers, and increase payment period and a certain degree of delay retirement In the future, the balance of pension insurance funds will be difficult to balance, and it is difficult to take responsibility for the burden of pension.

\section{MY COUNTRY'S PENSION FUND PAYMENT}

At present, the calculation formula of urban workers' pensions is the national unity, and the pension of employee insured personnel is mainly composed of basic pensions and personal account pensions.

Basic pension $=[$ The province $/$ city's annual social average salary * (1+ employee my average payment index)] / $2 *$ Payment period $* 1 \%$

Personal account pension $=$ personal account accumulated storage / number of month

According to the calculation formula of the basic pension, it is not difficult to see the level of the basic pension to hook three factors with the average annual 
payment index of the province / city, the average payment index and payment of the employees. Personal account pension is related to the total number of stores and number of months, and the accumulated storage of personal accounts is to be divided into personal accounts in accordance with $8 \%$ of the employee payment base. In order to calculate a interest rate according to the individual account accounting interest rate published by the Ministry of Tires, which is unified annually.

At present, there is only the incentive plan for the basic pension insurance of urban workers. From January 1, 2015, according to the "General Office of the People's Government of Jilin Province on the improved urban workers' basic pension insurance." Notice "(Ji Zheng Office Ming Power [2015] No. 11), for the new to receive basic pension conditions, I have more than 20 years of actual payment period, mainly two adjustments: first is in the original basic pension The proportion of the basic pension is increased by year. Second, the transition coefficient of transitional pension is raised from $1.2 \%$ to $1.4 \%$. The proportion of the basic pension is adjusted as shown in the following table: The accumulated payment period of employees arrived 2125 years, an increase of $0.15 \%$ per year. The accumulated payment period is $26-30$ years, an increase of $0.2 \%$ per year; the accumulated payment period is 31 years and more, an increase of $0.25 \%$ per year.

For the payment of personal accounts, my country has not yet proposed specific programs, only uniform and adjustment of accounting interest rates for personal accounts. In 2016, the state human society and the Ministry of Finance announced that the accounting rate of pension individual accounts was as high as $8.31 \%$, 2017, 2018, 2019, 2020, account interest rates were $7.12 \%, 8.29 \%, 7.61 \%, 6.04 \%$, these individuals. The account is far higher than the complimentary bank deposit financial interest rate. The accounting interest rate of personal accounts should mainly consider factors such as social average wage growth and balance of balance of pension funds, and then adjust it through reasonable coefficients, so that the accounting interest rate of the individual account shall not be lower than the bank periodic deposit rate. However, this annual release of unified personal account accounting interest rates, although there is currently a large excitation, personal account accounting interest rate is too high, and it is difficult to maintain the balance of balance of funds in the future, and this unified Accounting interest rate lacks incentives for long-term payment.

At present, it is highly incentive, but the personal account accounting interest rate is too high. It is difficult to maintain the balance of balance of funds in the future, and this unified accounting interest rate is lacking incentive for long-term payment.

\section{DESIGN OF PENSION PERSONAL ACCOUNT PAYMENT INCENTIVE PLAN}

According to the basic pension payment incentive plan proposed by Jilin Province, this paper draws on the idea of pensions, from the year of segmentation gradient, starting from the interest rate of individual accounts, and design four personal account payment incentives according to the payment period.

The payment incentive program for personal accounts is mainly to take a segmentation value for the accounting interest rate of the individual account. According to the "State Council's decision to establish a unified enterprise employee's basic endowment insurance system, the accounting rate of personal accounts is required every year. The interest rate calculation interest rate will be calculated from the bank's class deposit rate. According to 2021, China's six state-owned banks have a average annual interest rate of $2.04 \%$ for the average annual interest rate of $2.04 \%$, in five years as a gradient, divided into 1-5 years, 610years, 11-15years, 16 - 20years , 21-25 years, 2630years, 31-35years, 35-40years, 41 years of nine gradients, the program will gradually improve the accounting rate of personal accounts at $0.4 \%$, and the program is $0.6 \%$ Proportion gradually improves the accounting interest rate of the personal account, and the program three gradually improves the accounting interest rate of the personal account with a ratio of $0.8 \%$, and the plan is gradually improved by $1 \%$ scale to improve the accounting interest rate of the personal account. The specific scheme is Table 1. In this way, as the payment time is longer, the higher the accounting rate of the personal account, the higher the pension treatment obtained after the employee retirement.

Table 1. Personal account accounting interest rate scheme design

\begin{tabular}{ccccccccc}
\hline $\begin{array}{c}\text { Years } \\
\text { of payment }\end{array}$ & \multicolumn{1}{c}{$\begin{array}{c}\text { Pr } \\
\text { ogram1 }\end{array}$} & $\begin{array}{c}\text { Pr } \\
\text { ogram 2 }\end{array}$ & ogram3 & ogram 4 \\
\hline $1-5$ & & 2.0 & & 2.0 & & 2.0 & & 2.0 \\
& 4 & & 4 & & 4 & & 4 & \\
$6-10$ & & 2.4 & & 2.6 & & 2.8 & & 3.0 \\
& 4 & & 4 & & 4 & & 4 & \\
$11-15$ & & 2.8 & & 3.2 & & 3.6 & & 4.0 \\
& 4 & & 4 & & 4 & & 4 & \\
$16-20$ & & 3.2 & & 3.8 & & 4.4 & & 5.0 \\
& 4 & & 4 & & 4 & & 4 & \\
$21-25$ & & 3.6 & & 4.4 & & 5.2 & & 6.0 \\
& 4 & & 4 & & 4 & & 4 & \\
& & 4.0 & & 5.0 & & 6.0 & & 7.0
\end{tabular}




\begin{tabular}{lcccccccc}
\multicolumn{8}{c}{ Table l, cont } \\
31-35 & & 4.4 & & 5.6 & & 6.8 & & 8.0 \\
& 4 & & 4 & & 4 & & 4 & \\
$35-40$ & & 4.8 & & 6.2 & & 7.6 & & 9.0 \\
& 4 & & 4 & & 4 & & 4 & \\
$41-$ & & 5.2 & & 6.8 & & 8.4 & & 10. \\
& 4 & & 4 & & 4 & & 04 & \\
\hline
\end{tabular}

Source: This article is calculated

\section{EVALUATION OF THE PENSION PERSONAL ACCOUNT PAYMENT INCENTIVE PROGRAM}

In order to verify the various payment incentives, from the motivation and steady and long-term departure, this paper will compare the accounting interest rate, the social average wage growth rate, the social security fund investment yield, and the national social security fund investment yield. Thereby selecting a most reasonable payment incentive program.

According to Table 1, the average accounting rate of individual accounts in various years, the fifth year, for the decade, the fifteenth year, and the average value calculation of each program will be calculated, and the average accounting interest rate of the program is calculated. It the average accounting rate of program one was $2.84 \%$, and the average accounting rate of program two was $3.24 \%$, and the average accounting rate of program three was $3.64 \%$, and the average accounting rate of program four was $4.04 \%$.

\subsection{Bank Regular Deposit Rate}

Select the bank's regular deposit rate as a test indicator because the employee participates in urban workers' pension insurance is also an investment behavior. If people receive the rate of return, people will choose to deposit the money into the bank, produce abandoned behavior. The average interest rate of the personal account is contrast to the six major banks regular deposit rate (Table 2).
Table 2. Six state-owned banks regular deposit interest rate Data

\begin{tabular}{cllll}
\hline Bank & 1 year & 2 year & 3 year & 5 year \\
name & & & & \\
\hline PSBC & 2.15 & 2.95 & 3.84 & 3.44 \\
CCB & 2.07 & 2.9 & 3.81 & 3.75 \\
ABC & 2.02 & 2.81 & 3.65 & 3.5 \\
BOC & 2.03 & 2.82 & 3.67 & 3.55 \\
ICBC & 1.98 & 2.74 & 3.57 & 3.53 \\
BCM & 1.98 & 2.69 & 3.51 & 3.5 \\
Mean & 2.04 & 2.82 & 3.68 & 3.55 \\
\hline
\end{tabular}

Source: Interest Rate Meter Information Network

The average accounting rate of the program one is $2.84 \%$, close to the interest rate mean of deposits in the two-year regular deposit, the average accounting interest rate of the program two is $3.24 \%$, and between the twoyear regular deposit rate and the three-year regular deposit rate, the program The average accounting interest rate of the program three is $3.64 \%$, close to the interest rate mean of three years of regular deposits, and the average accounting interest rate of the program four is $4.04 \%$ higher than the periodic deposit rate of the bank's age. From the excitation of the individual account accounting interest rate payment incentive scheme, program four> program three> program two> program one have greater excitement.

\subsection{Social Average Salary Growth Rate}

Select a social average wage growth rate as a test indicator, because social average wage growth rate is inseparable with pension replacement rates. In order to ensure the stability of the pension system, we need to ensure that incentive programs can be responsible for the current and future pension. According to the China's economic and social data research platform, the average social average salary and its growth rate is known, and the present is $9.81 \%$ in the next five years according to its development trend. If the accounting interest rate of the personal account is far below the growth rate of social average salary, the personal account in this situation cannot provide the corresponding pension alternative, violating the original intention of the design of the urban workers' basic pension insurance system. According to the average interest rate of the personal account, it can be learned from the stability of the personal account accounting interest rate payment incentive plan, and the program four>program three>program two>program one. The highest interes rate of the program one is $5.24 \%$, the highest interest rate of the program two is $6.84 \%$, and the personal account accounting interest rate of these two programs is far below $9.81 \%$ of the salary growth rate in the next 
five years. From the steady side, the program Three and program four have a large stability.

\subsection{National Social Security Fund Investment Yield}

Choosing the national social security fund investment rate as a test indicator is because the National Social Security Foundation is a commissioned management of national social security funds and is responsible for personal account pilot provinces and cities basic endowment insurance personal account central subsidies, and personal accounts managed by the entrusted management Funds and their investment income. If the accounting interest rate of the personal account is too much higher than the investment yield of the National Social Security Foundation, it is difficult to maintain the balance of payments in the fund. At the same time, it will also cause a large pension burden on the national finance. $\mathrm{He}$ has long, which is not conducive to urban workers. Long-term development of the pension insurance system. The social security fund has been $8.14 \%$ of the annual investment yield since its establishment, and the specific annual investment yield is as follows. The average accounting interest rate of program one is $2.84 \%$, the average accounting rate of program two is $3.24 \%$, and the average accounting rate of program three is $3.64 \%$, and the average accounting rate of program four is $4.04 \%$. From the long-term perspective of personal account accounting interest rate payment incentives, program one>program two>program three>program four. However, with the increase of the payment period, the personal account accounting interest rate after the payment period arrived at 31 years begins more than the annual investment yield of the National Social Security Fund, and the program four is too high because the personal account accounting interest rate is too high. The most difficult rise in the long run.

\section{CONCLUSIONS}

From the motivation of the personal account, the accounting interest rate of the personal account is naturally better, but in terms of the system stability, the accounting interest rate of the individual account is not easy. Therefore, on the whole, the gradient of program three is merely $0.8 \%$ every five years, and accordingly makes program three the most suitable personal account payment incentive program.

\section{REFERENCES}

[1] Chen zhengshun, Li Aiqi, my country's Cultivation of Subject Nobular Endowment Insurance System Current Situation, Problems [J], Economic Research Reference, 2020 (07): 37-47

[2] $\mathrm{Mu}$ Huaizhong, Li Chen, Longevity Risk on the Impact Effect of Personal Account Balance of Subject Endowment Insurance of Urban Workers [J], Population and Development, 2020, 26 (06): 2$12+51$

[3] Qin Fei, Zhang Jing, analysis of basic pension insurance interruption of urban workers [J], Sichuan Labor Guarantee, 2020 (11): 29

[4] Dong keyong, pension development status, challenge and trend research _ Taking the basic pension system of urban workers as an example [J], People Forum, 2019 (26): 92-94

[5] Xue Huiyuan, Yue Xiao, He YanTing, thinking about adjusting the number of months of the basic endowment insurance of urban workers [J], Decision and Information, 2019 (10): 47-53

[6] Yu Jie, improved the countermeasures of the basic pension insurance of urban workers [D], Northeast University of Finance and Economics, 2017

[7] Wang Cuoqin, Xue Huiyuan, the design, assessment and selection of basic pension insurance for urban workers [J], Journal of Jiangxi University of Finance and Economics, 2017 (01): 69-80

[8] Li Zhen, Huang Wanding, the basic endowment insurance of urban workers $[\mathrm{J}]$, Journal of the National Institute, 2016 (05): 49-54 + 142

[9] Xue Huiyuan, Song Jun, Urban Workers Basic Endowment Insurance Personal Accounts Internal Return Rate Measurement and Analysis [J], Insurance Research, 2015 (09): 117-127

[10] Notice of the General Office of the People's Government of Jilin Province on improving the basic pension insurance of urban workers $[\mathrm{J}]$, Jilin Conduct, 2015 (05): 40 